\title{
AN APPLICATION OF CADASTRAL FABRIC SYSTEM IN IMPROVING POSITIONAL ACCURACY OF CADASTRAL DATABASES IN MALAYSIA
}

\author{
Tan Liat Choon ${ }^{1}$, Lai Chaim Ho ${ }^{2}$, Ujang Uznir ${ }^{1}$, Ai Chin Thoo ${ }^{3}$, Azri Nor Suhaibah ${ }^{1}$, Kam Seng Looi ${ }^{4}$, Ming Liang Toh ${ }^{1}$, \\ Wee Vern Tan ${ }^{1}$, Kathitasapathy Shanmugapathy ${ }^{1}$, Joun Ann Geh ${ }^{1}$ \\ ${ }^{1}$ Department of Geoinformation, Faculty of Built Environment and Surveying, \\ Universiti Teknologi Malaysia, 81310, Skudai, Johor, Malaysia \\ tanliatchoon@gmail.com,mduznir@utm.my, suhaibah@utm.my, mltoh217@gmail.com,wvtan2@live.utm.my, \\ pathyjr@hotmail.com, jouen451@gmail.com \\ ${ }^{2}$ Landsoft Sdn Bhd, 38C, 4, Jalan Radin Anum, Bandar Baru Sri Petaling, 57000, Kuala Lumpur, Malaysia \\ laich@mapit.com.my \\ ${ }^{3}$ Azman Hashim International Business School, Universiti Teknologi Malaysia, 81310, Skudai, Johor, Malaysia \\ acthoo@utm.my \\ ${ }^{4}$ Department of Survey and Mapping Malaysia, Jalan Yahya Petra, Kampung Datuk Keramat, 54000, Kuala Lumpur, Malaysia \\ looi@jupem.gov.my
}

Commission 4, WG 7

KEY WORDS: Cadastral Fabric, Cadastral Fabric System Software, NDCDB, Coordinated Cadastral System, Positional Accuracy Improvement.

\begin{abstract}
Cadastral fabric is perceived as a feasible solution to improve the speed, efficiency and quality of the cadastral measurement data to implement Positional Accuracy Improvement (PAI) and to support Coordinated Cadastral System (CCS) and Dynamic Coordinated Cadastral System (DCCS) in Malaysia. In light of this, this study aims to propose a system to upgrade the positional accuracy of the existing cadastral system through the utilisation of the cadastral fabric system. A comprehensive investigation on the capability of the proposed system is carried out. A total of four evaluation aspects is incorporated in the study to investigate the feasibility and capability of the software, viz. performance of geodetic least squares adjustment, quality assurance techniques, supporting functions, and user friendliness. This study utilises secondary data obtained from the Department of Surveying and Mapping Malaysia (DSMM). The test area is coded as Block B21701 which is located in Selangor, Malaysia. Results show that least square adjustment for the entire network is completed in a timely manner. Various quality assurance techniques are implementable, namely error ellipses, magnitude of correction vectors and adjustment trajectory, as well as inspection of adjusted online bearings. In addition, the system supports coordinate versioning, coordinates of various datum or projection. Last but not least, user friendliness of the system is identified through the software interface, interaction and automation functions. With that, it is concluded that the proposed system is highly feasible and capable to create a Cadastral Fabric to improve the positional accuracy of existing cadastral system used in Malaysia.
\end{abstract}

\section{INTRODUCTION}

With the advancement of Information and Communications Technology (ICT), this era features digitalised data that are accurate, accessible and efficient. Similar phenomenon happens in the field of survey and mapping. Over the past decades, cadastral survey in Malaysia has undergone dramatic changes in the aspect of technical, operational, structural and institutional. Such evolvements are associated with the development of the latest technologies, inter alia, Global Navigation Satellite System (GNSS), Geographic Information System (GIS), and digital cadastral databases. As stated by Williamson et al. (2010), advanced technology plays an indispensable and crucial role in ensuring the functionality of a land administration system. Thus, the Department of Surveying and Mapping Malaysia (DSMM) has initiated a series of cadastral database reform, starting from the introduction of Computer Assisted Land Survey System (CALS) in 1992, Cadastral Data Management System (CDMS) to repopulate the Digital Cadastral Database (DCDB) in Peninsular Malaysia in the year of 1998, and Coordinated Cadastral System (CCS) via the eCadaster project (Hashim et al, 2016). It is worth noting that CCS facilitates the implementation of a homogeneous cadastral database known as National Digital Cadastral Database System
(NDCDB). To date, NDCDB is being used as a coordinatebased cadastral database which is based on geocentric datum (GDM2000) with a uniform spatial accuracy of less than $10 \mathrm{~cm}$ throughout the whole peninsular Malaysia (Choon and Seng, 2014; Choon et al., (2015; 2016a; 2016b; 2018a; 2018b)). This datum is applied for positioning and mapping activities in Malaysia, which including lot, mukim, district, state and national boundary with the sufficient control points along the boundaries.

However, GDM2000 network shifts about $3 \mathrm{~cm}$ per year towards the East-Southeast direction and within 20 years, the GDM2000 coordinates would have already changed by about $60 \mathrm{~cm}$ without considering the effects of earthquakes (Rasidi, 2016). However, Azmi (2020) stated that the mapping datum used in NDCDB is outdated since it referred to GDM2000 with the reference frame of ITRF2000, while GNSS applications adopt the latest global reference frame, which is ITRF2014. Therefore, the reliability of mapping datum for NDCDB needs to be assessed and revised frequently, in order to maintain the consistency, precision and accuracy of geospatial database with respect to the latest positioning datum. The kinematic datum is causing continuous changes of coordinates and it eventually poses critical issues, especially in the cadastral database which fails to undergo 
regular updates. As such, the position accuracy of the NCDCB is at stake due to dynamic changes of the datum used by the system. Researches with methods of positional accuracy improvement (PAI) of cadastral geospatial data have gained attention and emerge as a topic of interest worldwide (Ceh al., 2019). In light of this, this study aims to propose an approach to upgrade the positional accuracy of the existing cadastral system used in Malaysia through the utilisation of the cadastral fabric system. At the same time, a comprehensive investigation on the capability of the proposed system is carried out.

The Cadastral Fabric System (CFS) in this study stores all information of the cadastral network in its Fabric Database and configures the input for adjustment on the fly during adjustment. Adjustments can be activated with control coordinates of any epoch available in the Fabric Database, which could be a different set of controls from one epoch to another. Hence, the chance in coordinates of control points between epochs are not material to the adjustment, but all controls in one adjustment must be of the same epoch. With the adjusted coordinates of the different epochs, the trajectory of the shifts can be determined. With the Fabric System's ability to maintain adjusted coordinates of different epochs, adjustments can be performed as regularly as deemed necessary, with improved positional accuracy when more controls are being introduced into the cadastral network.

\section{CADASTRAL FABRIC SYSTEM}

Cadastral fabric is not a new concept. In fact, the Environmental Systems Research Institute (ESRI) released the Cadastral Fabric as a collaborative effort with Geodata of Australia in the year 2007 (Foster \& Blanford, 2013). Put simply, it is a continuous 'fabric' or surface of connected parcels that model the real world (Huong, 2010; Harper, 2010). Cadastral fabric functions as a base map to improve the spatial accuracy of other Geographic Information System (GIS) layers in a cadastral database (Elfick and Hodson, 2006). On the other hand, Cadastral Fabric System (CFS) consists of a software component and a fabric database. The fabric database contains all the explicit topological relationships between markers, boundaries and lots in the cadastre. The fabric database has been designed as a repository of all cadastral survey entities and stores both historical and current data in one integrated design. It is worth noting that CFS is an independent system which can be implemented parallel to the existing systems (Tim, 2020). The cadastral fabric is introduced to assess the Coordinated Cadastral System (CCS) and Positional Accuracy Improvement (PAI) in the existing system. The cadastral fabric system not only to support the CCS, but also overcome the issue in the NDCDB. In addition, cadastral fabric is also a system to implement Positional Accuracy Improvement (PAI) to improve the current digital cadastral database and upgrade the accuracy of coordinates in the existing systems.

\subsection{Positional Accuracy Improvement}

Positional Accuracy Improvement (PAI) is the process of improving the position of the coordinates defining the geometry of a feature in a geospatial dataset to better reflect its "true" position. The "true" position can either relate to the absolute position in an overarching Coordinate Reference System or to the relative position in relation to the geometry of another feature in the vicinity. PAI is significant for a geospatial database in order to improve the positional accuracy of cadastral data according to reference geographic data on the same scale to fit with more accurate national geographic data (Dong, 2019).
Figure 1 illustrates the process of Positional Accuracy Improvement of the parcel.

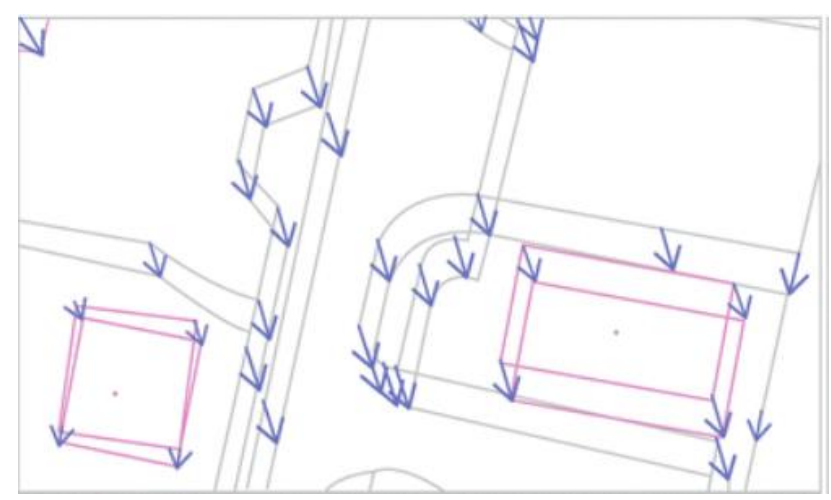

Figure 1. Positional Accuracy Improvement (PAI)

\subsection{Cadastral Fabric System Software: An Operational Framework}

The Cadastral Fabric System software (CFSS) is a fully integrated numerical graphic system specifically developed for the implementation of cadastral fabric to cater for the cadastral survey industry's numeric mapping and coordinated cadastre system (CCS) requirements. CFSS is a multi-user system with a centralized fabric database. It is developed by using in-house developed $\mathrm{C}++$ geographic graphic engine codenamed CppGIS. CppGIS is a core interactive graphics system developed and enhanced over the years and have been the base system for a number of implementations.

Various evaluation aspects are incorporated in the study for the investigation of the feasibility and capability of the software. There is a total of four aspects as shown in Figure 2. Least Square adjustment (LSA) is crucial in improving and maintaining the spatial accuracy of the cadastral fabric (Huong, 2010, Foster \& Blanford, 2013). LSA is widely used in the field of cadastral survey as a common method to improve the positional accuracy (Hashim et al., 2017). This makes the performance of the software in terms of Geodetic Least Squares Adjustment as one of the top criteria to evaluate. Elfick et al. (2005) highlighted on the appropriate ways to assess the quality of a cadastral fabric, inter alia, misclosure of each parcel, residuals resulting from least square adjustments, and the magnitude of displacement vectors. Proper Quality Assurance is mandatory due to the variety of data with different quality (Elfick et al., 2005). It is vital to track the spatial accuracy of each parcel block (Taylor, 2008). Thus, the comprehensiveness of quality assurance techniques remains a vital aspect in evaluating the cadastral fabric system. Next, Schuurman et al. (2006) noted that one of the problems which may occur in building a seamless cadastral fabric is the differences in spatial attributes. This reflects the need for a system to support coordinate versioning, coordinates of various datum and map projections. Foster (2011) added that the accuracy assignment is important in the adjustment process as data with higher accuracy shall be assigned with higher weightage compared to data with lower accuracy. In order to implement accuracy assignment, the system must be able to perform concurrent adjustment of current and old measurements. Also, the ability to retain historical data is one of the critical components of a cadastral fabric (Taylor, 2008). Last but not least, the CFSS must demonstrate the element of user-friendly since it is a multi-user system. User friendliness can be easily identified 
through the software interface, interaction and automation functions.

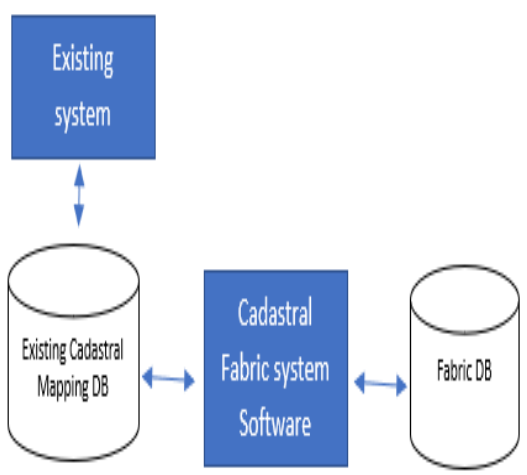

CFSS operating engine

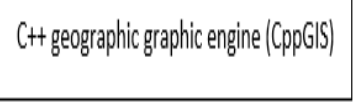

CFSS Database Management System

SQLServer, Oracle, PostGIS

\section{Design 0 jective}

To achieve Positional Accuracy Improvement (PAI) objective for the current NDCDB dataset to support the implementation of Cooddinated Cadastral System (CCS) and the Dynamic Coordinated Cadastral System (DCCS)

\begin{tabular}{|c|}
\hline Key Evaluation Aspects \\
\hline 1) Performancc of the software in terms of Geodetic Least Squares Adjustment. \\
\hline 2) Comprehensive quality assurance techniques. \\
\hline $\begin{array}{l}\text { 3) Crcial supporting functions: (i) coordinate versioning, coordinates of various } \\
\text { datum or projection as well as all national and state projections (ii) Concurrent } \\
\text { adjustment of current and old measurements }\end{array}$ \\
\hline 4) User Friendliness. \\
\hline
\end{tabular}

Figure 2. Operational Framework

\section{METHODOLOGY}

Aforementioned, the aim of this study is to propose a feasible solution to improve positional accuracy of the existing systems through the utilisation of the cadastral fabric system. The cadastral fabric system encompasses a software component (hereafter known as cadastral fabric system software (CFSS)) and a fabric database. CFSS was developed for the said purpose. On the other hand, the workflow to create the fabric database in shown in Figure 3.
Figure 3. Cadastral Fabric Database Creation Process Flow

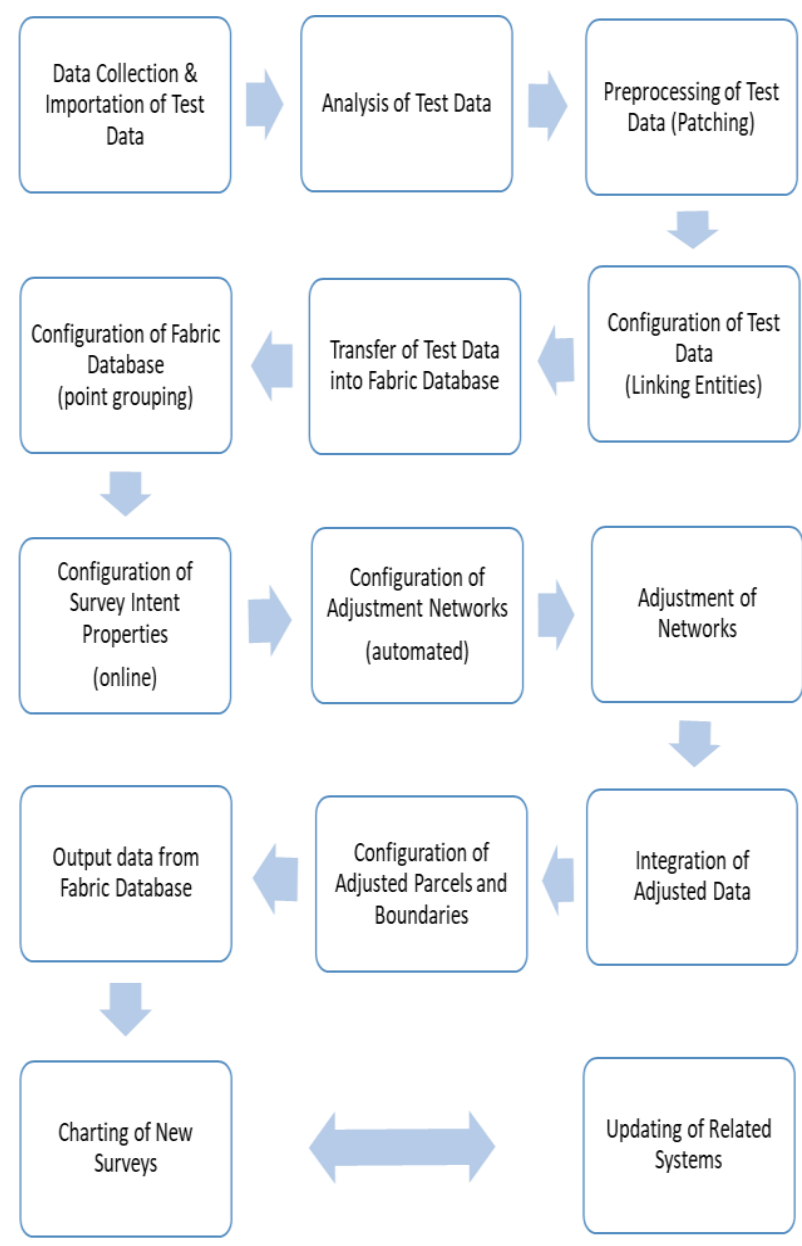

In general, the workflow involves six main stages. First, a preliminary study on the test data. This study utilises secondary data obtained from the Department of Surveying and Mapping Malaysia (DSMM). The test data come in various formats, namely Mapinfo files and ASCII files which contain the necessary information for the creation of the test cadastral fabric database. Steps have been taken to ensure the geometry consistency as well as data adequacy and completeness prior to the next stage. As concluded by Looi et al., 2021, the primary aspect to achieve accurate results is to input the data free from errors. The study area encompasses Block B21701 which is located in Selangor, Malaysia (Figure 4). The second stage involves the Pre-processing of test data. Here, the configuration of marker, boundary and lot topology are carried out before the transfer of test data into Fabric Database. In the third stage, configurations are done in the Fabric Database, including markers grouping, configuration of online markers, assignment of apriori Standard Deviations to measurements, the definition of additional topological relationships and management of topological errors. The fourth stage is the network adjustment. Followed by the display, inspection and assessment of adjustment results in the fifth stage. Lastly, the adjusted data from the fabric database can be outputted and be used for the updating of related existing databases. 


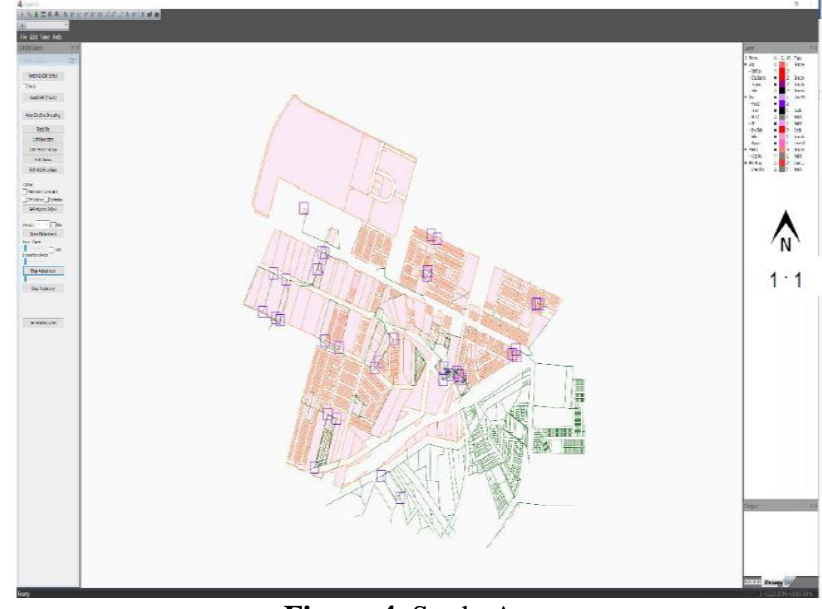

Figure 4. Study Area

Cadastral boundaries have been surveyed since the beginning of the system and Certified Plan is the only reliable records of survey measurements available. Hence, the bearings and distances depicted on Certified Plan would form the bulk of the primary data available for the creation of the Cadastral Fabric. This exercise utilizes the available non-adjusted record of bearings and distances captured from the Certified Plan. There is no extensive preprocessing required except various quality control tests to ensure that data or transcription errors, introduced during the original back capture exercise, are being kept to the minimum.

More work should be expected on the identification of the same cadastral position represented by the different markers on different Certified Plan, whether abuttals or new subdivisions, over time. In the event of an extended implementation, boundaries that are necessary and yet not available currently may need to be back captured from the Certified Plan to complete the dataset. Adding of new survey boundaries, due to the on-going cadastral survey activities, would be a natural progression of the Cadastral Fabric. This has been mentioned in the Process Flow Chart as 'Charting of New Surveys'.

The feasibility and capability of the cadastral fabric system in improving the PAI and current cadastral system can be assessed by using the evaluation aspects as stated in sub-section 2.2. A total of four aspects is adopted for the evaluation process. The results and performances of the CFSS are discussed in the following section.

\section{RESULTS AND DISCUSSIONS}

\subsection{Performance of the software in terms of Geodetic Least Squares Adjustment}

Adjustment was initially performed on a single test block and the results were found to be satisfactory. With the successful adjustment of all the test blocks, adjustment was performed on the entire test dataset and was successful. During this process, fixed control points are processed together with the recorded dimensions to derive adjusted and more accurate coordinates for parcel corners (Foster \& Blanford, 2013). The excerpt of the Adjustment Reports for a single test block as well as the entire dataset is shown in Figure 5 and 6 respectively. Based on the figure, the adjustments were converged after 2 iterations for the single test block and 3 iterations for the entire dataset. Notably, the total processing time for the Geodetic Least Squares
Adjustment is completed within 15 minutes. The adjustment software is a geodetic network adjustment software capable of supporting such parameters as the reference frame, epoch and geoid. This capability is not utilized in this exercise and hence not elaborated.

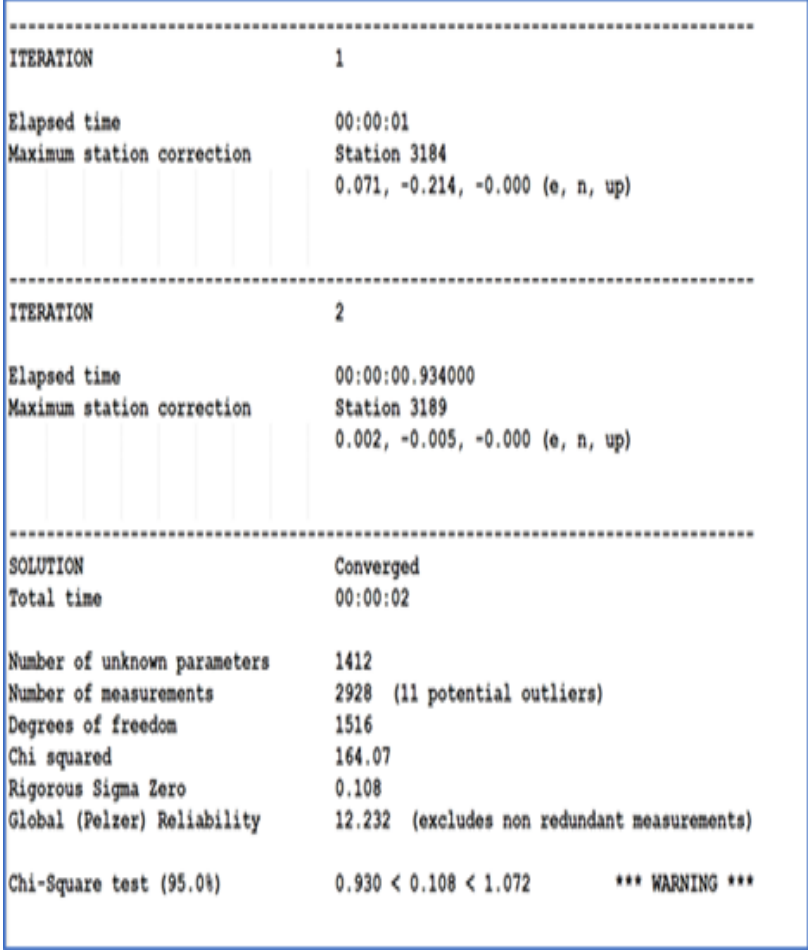

Figure 5. Adjustment Result for Single Test Block (Generated by System)

\begin{tabular}{|c|c|}
\hline ITERATION & 1 \\
\hline $\begin{array}{l}\text { Raapsed time } \\
\text { Maximum station correction }\end{array}$ & $\begin{array}{l}00: 03: 42 \\
\text { Station } 5386 \\
2.638,1.328,0.000(e, n, \text { up })\end{array}$ \\
\hline ITERATION & 2 \\
\hline $\begin{array}{l}\text { 81apsed tise } \\
\text { Maximum station correction }\end{array}$ & $\begin{array}{l}00: 03: 43 \\
\text { station } 5386 \\
-0.324,0.254,-0.000 \text { (e, n, up) }\end{array}$ \\
\hline ITERATION & 3 \\
\hline $\begin{array}{l}\text { 8lapsed time } \\
\text { Raximum station correction }\end{array}$ & $\begin{array}{l}00: 03: 42 \\
\text { station } 5389 \\
0.013,0.022,-0.000 \quad(0, \mathrm{n}, \text { up })\end{array}$ \\
\hline $\begin{array}{l}\text { 3olvtion } \\
\text { Potal tine }\end{array}$ & $\begin{array}{l}\text { Converged } \\
00: 11: 09\end{array}$ \\
\hline Wuaber of unknown parameters & 10908 \\
\hline Nuaber of measurements & 22983 (59 potential outliers) \\
\hline Degrees of freedom & 12075 \\
\hline $\begin{array}{l}\text { Chi squared } \\
\text { kigorous sigma zero }\end{array}$ & $\begin{array}{l}901.13 \\
0.075\end{array}$ \\
\hline Global (Pelzer) Reliability & 13.778 (exeludes non redundant measuresents) \\
\hline Chi-square test $(95.08)$ & $0.975<0.075<1.025$ \\
\hline
\end{tabular}

Figure 6. Adjustment Result for Entire Block (Generated by System) 


\subsection{Comprehensive Quality Assurance Techniques}

The CFSS contains functions to display the various adjustment results for inspection purposes. Quality assurance techniques are vital to improve the PAI of the existing system by managing blunders and errors in the dataset (Elfick et al. 2005).

4.2.1 Error Ellipses: Error ellipses at each point adjusted are displayed after the adjustment showing the possible errors at the points. Most error ellipses are very small and seen as small red dots. The red patches where larger ellipses are visible are areas not connected to the rest of the network and hence the control points and the estimated errors in these areas are large. To make the smaller ellipses visible, exaggeration factors have been applied to enlarge the display of error ellipses. However, this might result in large error ellipses which overlap with other areas. As a remedy, CFSS enables filters to be applied in order not to display those oversized error ellipses. Figure 7 (for illustration purpose) below shows the error ellipses after the adjustment.

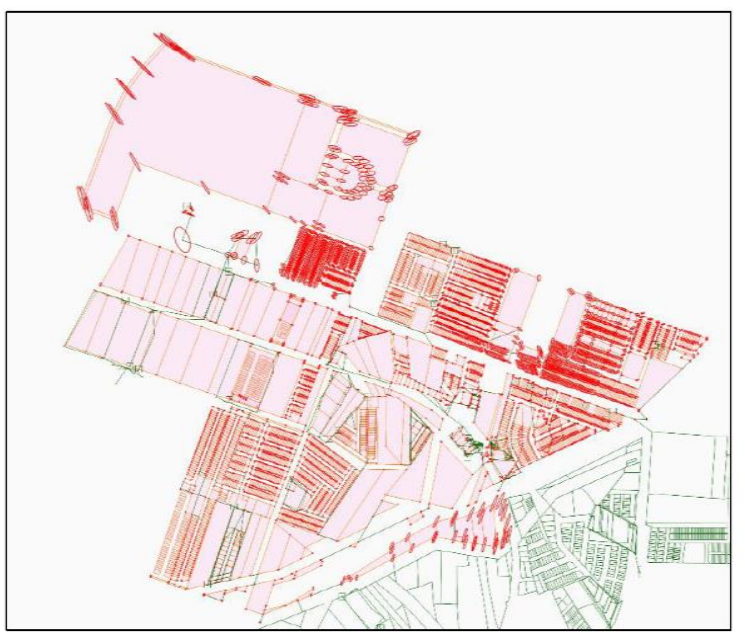

Figure 7. Enlarged Error Ellipses with Filter

4.2.2 Correction Vectors: CFSS displays the vectors indicating the corrections applied to each point in relative magnitude to each other. These so-called correction vectors indicate the relative amount of corrections applied at each of adjusted point. Similar to error ellipses, as the magnitude of these corrections are small, an exaggeration factor has been applied to make the relative sizes more visualisable as shown in Figure 8 (for illustration purpose).

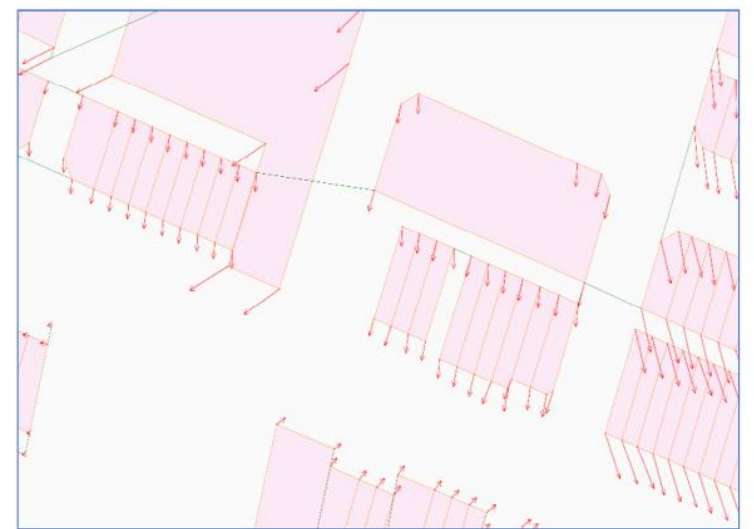

Figure 8. Correction Vectors of the Adjustment
4.2.3 Adjustment Trajectory: If there are more than one adjustment performed on the same area and the adjustment results have been stored with different version IDs, the adjustment correction trajectory applied in these adjustments can the displayed as shown in Figure 9 (for illustration purpose).
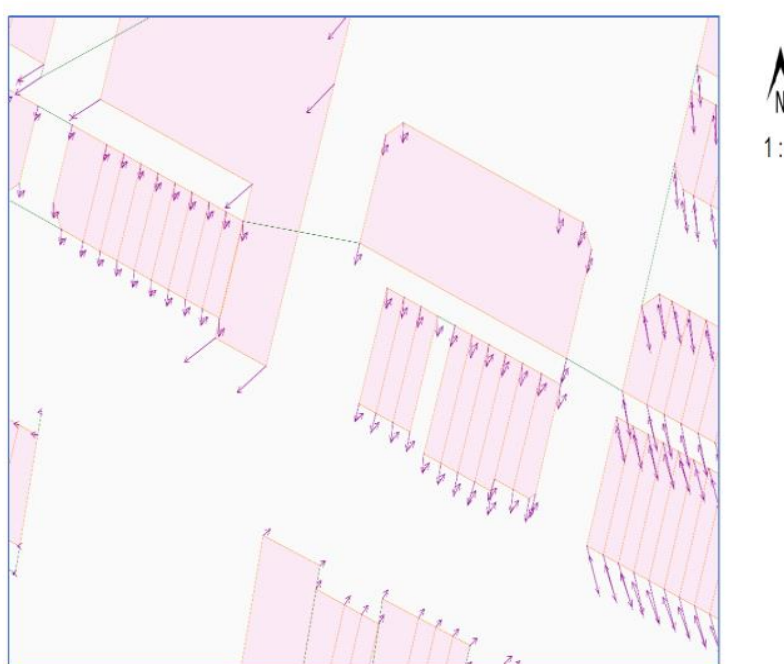

$1: 1$

Figure 9. Display of Correction Trajectory

4.2.4 Adjusted Online Bearings: To verify that the online property configured for a row of online markers indeed effective in controlling adjustments, CFSS allows the inspection of adjusted online bearings with the surveyed bearings. In the following Figure 10 (for illustration purpose), the adjusted bearings in NCDB are displayed for comparison purposes. The figure below shows that the boundary lines with online property configured has a maximum of 5 seconds spread, whereas those in the NDCDB dataset shows a spread of 43 seconds.

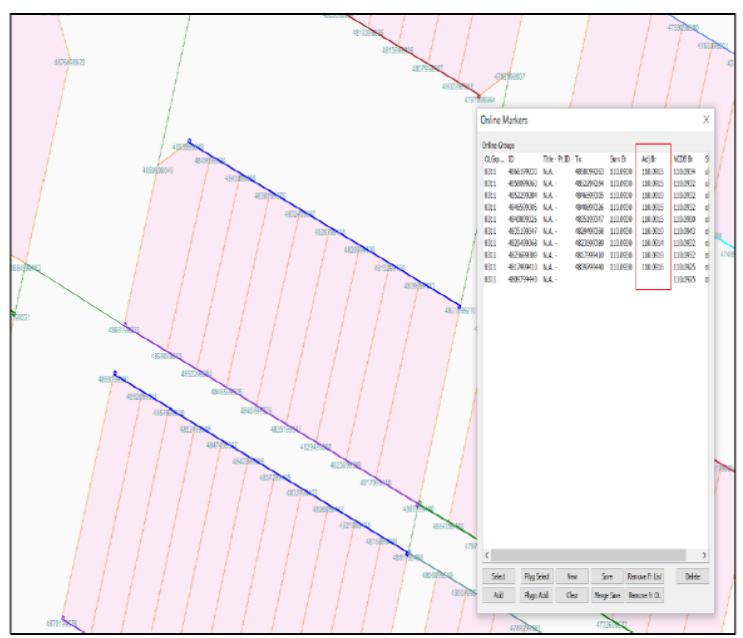

Figure 10. Display of Online Adjustment Results (Generated by System)

\subsection{Crucial Supporting Functions}

Certain functions are needed to cater for the multiple control networks or datums used in Malaysia. They are discussed in the following subsections. 
4.3.1 Support coordinate versioning, coordinates of various datum or projection as well as all national and state projections: Within the CFS is a state-of-the-art geodetic Least Squares Adjustment software embedded with the various state's GDM2000 Cassini and RSO projections in Peninsular Malaysia. All adjustments are carried out in the geodetic space and the results transformed back to the projected space when completed. Said otherwise, CFSS is capable of supporting multiple versions of coordinates from adjustments with different projection and/or datum of any epoch in the Fabric Database. When required, the CFSS enables the transformation between the GDM2000 and State Cassini projections as well as GDM2000 and RSO projections to cater for general mapping needs.

4.3.2 Concurrent adjustment of current and old measurements: The CFSS has been designed to be a repository that can accommodate measurements of different accuracies from digitised lines to control traverse lines. There are cases that one boundary line could have been digitised and surveyed multiple times during its existence and measurements with various accuracies recorded in the Fabric Database. During adjustment configuration, CFSS is able to detect this multiplicity and the measurement of the highest accuracy would be automatically utilised for the adjustment. Hence, survey measurements of differing accuracies could co-exist in the Fabric Database and will not affect the accuracy of adjustments. The software's ability to retain historical data is one of the critical components of a cadastral fabric (Taylor, 2008).

\subsection{User Friendliness}

Aforementioned, user friendliness is identified through the software interface, interactive and automation functions. A total of four aspects is discussed in the following subsection.

4.4.1 Integrated Database: The CFS contains an integrated Fabric Database. This integrated multi-user database maintains all data that is relevant to the fabric system. Enabling multiple users to insert, retrieve, update and adjust data at the same time. This integrated database is pertinent in the execution of automated functions, adjustment configuration, the management of multiple versions of coordinates and topological properties. The database can be implemented in a number of commercial database systems like SQL Server, Oracle or Open Source system like PostGIS.

4.4.2 Automation in adjustment configuration and optimization of adjustment: With a configured Fabric Database, the area for adjustment can be interactively defined and adjustments performed in an ad-hoc manner. The system would configure the adjustment input, execute the adjustment and display the results interactively on the screen as shown in Figure 11 and 12 (for illustration purpose). The automated adjustment configuration includes the retrieval of all markers and boundaries from the Fabric Database within the defined adjustment area; automatic configuration of adjustment networks; creation of adjustment input sets using surveyed lines of the best accuracy available; perform network adjustment; and display of error ellipses and correction vectors for inspection.
In addition, if the adjustment results are not optimal and exceed the higher limits of the $95 \%$ Confidence Level Chi-Squares Tests, CFSS could be set automatically to optimise the adjustments as so to achieve the required level of adjustment requirements.

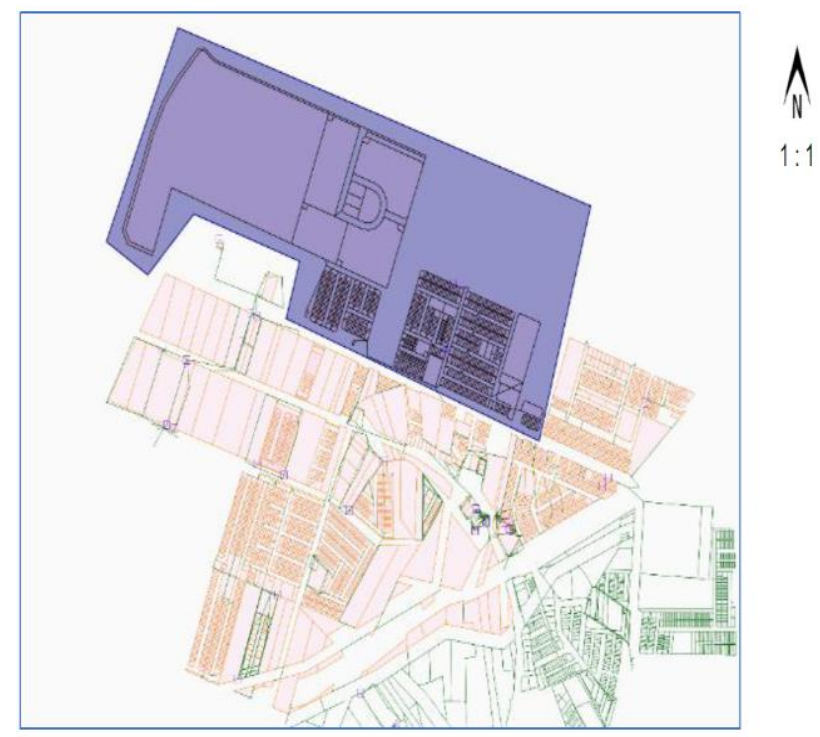

Figure 11. Interactive Selection of Block

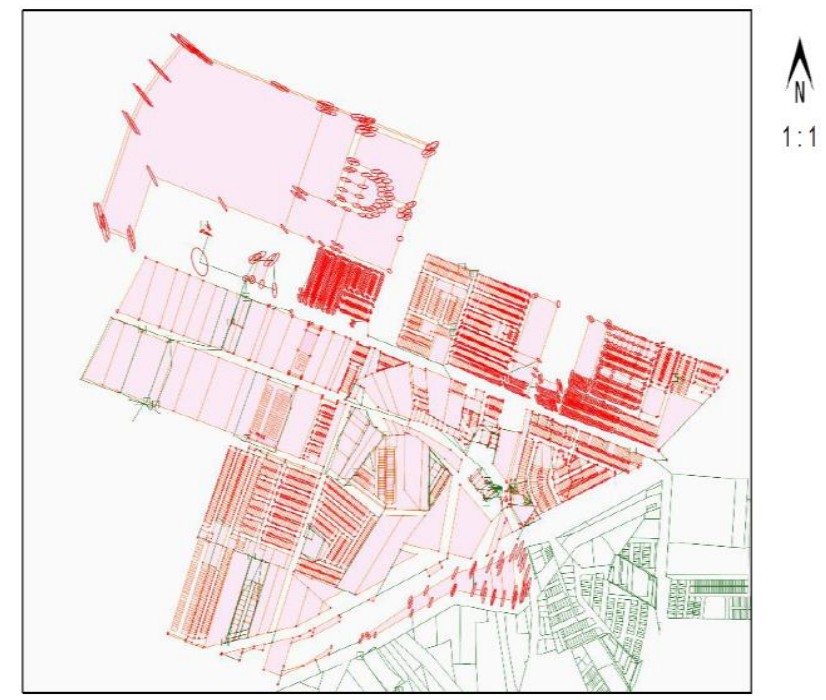

Figure 12. Adjustment Performed on Selected Block

4.4.3 Enable unlimited number of adjustment points: With this high compute ability, the software does not limit the number of points that can be adjusted simultaneously. The constraint on the number of points to be adjusted simultaneously is instead limited by the time allowed in the computation, the amount of computing power and the memory available in the hardware. If necessary, this adjustment can be performed in the cloud so that an even larger number of processors can be employed to complete the adjustment in shorter times. After the adjustment, the old boundary would be updated with the latest adjusted coordinates and be compatible and match with the latest map. 
4.4.4 Interactive or automated functions for points grouping: To transform, integrate and configure existing survey data from the various sources into the Fabric Database would be one most demanding exercise in developing the Cadastral Fabric. Numerous automated configuration functions have been incorporated into CFSS but there are cases where human decision and interaction are necessary to resolve issues that could not be automatically resolved. To lessen the effort in this exercise, CFSS contains various interactive editing and automated functions to cater for this purpose. Two types of data configuration have been mostly automated, but may require human decision for some situations, namely, markers grouping and online markers configuration.

\section{CONCLUSION AND RECOMMENDATIONS}

This study proposes a system to potentially improve the PAI in the existing cadastral system. In achieving the overarching aim, this study concludes that CFSS is highly feasible and capable to create a cadastral fabric which in turn upgrade the positional accuracy of the existing cadastral system used in Malaysia. The concept of cadastral fabric is not new, but it is still practical and implementable in Malaysia. However, further study should be conducted on the (i) inclusion of historic lots to strengthen the configuration of adjustment network, (ii) availability of more surveyed connection lines between blocks, and (iii) availability of a new subdivision for automatic charting and staged adjustment to include the new subdivision in the Fabric Database.

\section{ACKNOWLEDGEMENTS}

This work is partially supported by the UTM Research University Grant Vote Q.J130000.2652.16J68 and also thanks to Landsoft Sdn. Bhd.

\section{REFERENCES}

Azmi, M.I, 2020: Study on Cadastral Surveying for Demarcation of Boundary Mark Using GPS Technique. Faculty of Built Environment and Surveying, Universiti Teknologi Malaysia.

Ceh, M., Frank, G., Barbara, T., Mateja, K., and Anka, L., 2019: Improving the Positional Accuracy of Traditional Cadastral Index Maps with Membrane Adjustment in Slovenia. ISPRS International Journal of Geo-Information 8, no. 8: 338. https://doi.org/10.3390/ijgi8080338.

Choon, T. L., \& Seng, L. K., 2014: Developing Infrastructure Framework to Facilitate the Malaysian Multipurpose 3D Cadastre. Kuala Lumpur, Malaysia, 1-21.

Choon. T. L., Zulkifli, N. A., Ujang, M. U. and Chin, T. A., 2015: Malaysian Land Administration Domain Model Country Profile. Asian Social Science. 11 (24), 301-314. http://dx.doi.org/10.5539/ass.v11n24p301.

Choon, T. L., Ujang, M. U., Chin, T. A., Hasan, M. H. A. and Shah, S. Nur W. M., 2016a: New Strata Rights in Malaysia. In: Proceedings of the 2nd Sustainability Initiatives: Case Studies in Malaysia, Philippines and Indonesia and International Conference on Urban Studies (2nd SIMPI 2016). 4-5 May 2016. Manila, Philippines.

Choon, T. L, Ujang, M. U., Chin, T. A., Eng, S. E., Sen, L. G., Hasan, M. H. A. and Shah, S. Nur W. M., 2016b: Condominium
Rights in Malaysia. Advanced Science Letters. 22 (12), 41944196. http://dx.doi.org/10.1166/as1.2016.8100.

Choon, T. L., Ujang, M. U., Chin, T. A., and Chuan Y. B., 2018a: Three-Dimensional Land Legislation in Malaysia. In: Proceedings of the 2nd International Symposium on Social Sciences, Arts and Humanities (SYSSARM 2018). 20 March 22 March 2018. Krabi, Thailand.

Choon, T. L., Siow, W. J., Latif, S. A. A. and Zulkiflee, A. B., 2018b: Land Acquisition at Strata and Stratum Scheme in Malaysia. In: Proceedings of the 39th Asian Conference on Remote Sensing (ACRS 2018). 15 October - 19 October 2018. Kuala Lumpur, Malaysia.

Dong, T. B. P., 2019: Positional Accuracy Improvement for Heterogeneous Geodata Integration. FIG Working Week 2019, Hanoi, Vietnam.

Elfick, M. and Hodson, T., 2006: Managing Cadastral Data. GIS, XXIII FIG Congress, Munich, Germany, October 8-13, 2006.

Elfick, M., Hodson, T. and Wilkinson, C., 2005: Managing a Cadastral SDI Framework Built from Boundary Dimensions. Presented at FIG Working Week 2005 and GSDI-8, Cairo, Egypt April 16-21, 2005.

Foster, L. M., 2011: Improving Cadastre: Development of a Workflow Prototype Utilizing Esri's Parcel Fabric. MGIS Capstone Project - Geog 596B, Summer 2011.

Foster, L. M. and Blanford, J. I., 2013: Improving Cadastre: Development of a Workflow Prototype Utilizing ESRI's Parcel Fabric, Journal of the Urban and Regional Information Systems Association, Vol. 25, No. 2, 2013.

Hashim, N.M., Omar, A.H., Ramli, S.N.M., Omar, K.M. and Din, N., 2017: Cadastral Database Positional Accuracy Improvement. International Archives of the Photogrammetry, Remote Sensing \& Spatial Information Sciences, 42(4), p91-96. DOI: 10.5194/isprs-archives-XLII-4-W5-91-2017.

Harper, I., 2010: The New Technology of a Survey Data Model and Cadastral Fabric as the Foundation for a Future Land Administration System. Presented at FIG Congress 2010, Sydney, Australia, 11-16 April 2010.

Huong, D., 2010: The application of arcgis cadastral fabric model for cadastral database management. In International Symposium on Geoinformatics for Spatial Infrastructure Development in Earth and Allied Sciences. Http://wgrass. media. osaka-cu. ac. jp/gisideas10/viewpaper. php.

Looi, K.S., Chan, K.L., Isahak, M.F., Hamzah, H., Muda, N., Lim, B.W., Yeap, W.C. and Tan, L.C., 2021: Conventional Approach to Harmonious Coordinated Cadastral Database Weakness. In IOP Conference Series: Earth and Environmental Science. Vol. 767, No. 1. doi:10.1088/1755-1315/767/1/012018.

Rasidi, S., 2016: Current status of Geocentric Datum of Malaysia 2000 (GDM2000), JUPEM.

Schuurman, N., Leszczynski, A., Fiedler, R., Grund, D. and Bell, N., 2006: Building an integrated cadastral fabric for higher resolution socioeconomic spatial data analysis, Progress in 
Spatial Data Handling. Springer, Berlin, Heidelberg, pp 897920.

Taylor, B., 2008: Cadastral Evolution in British Columbia. Proceedings of the Canadian Hydrographic and National Surveyors Conference 2008
Tim, H, 2020: Maintaining Cadastral Measurement Data in the Parcel Fabric. FIG Working Week 2020. Amsterdam, the Netherlands.

Williamson, I. P., Enemark, S., Wallace, J., and Rajabifard, A., 2010: Land Administration for Sustainable Development (1st ed.). California, ESRI, 